\title{
Historical aspects in pain management in palliative care in an oncological reference unit
}

\author{
Aspectos históricos no manejo da dor em cuidados paliativos em uma unidade de referência oncológica \\ Aspectos históricos en el manejo del dolor en cuidados paliativos en una unidad de referencia oncológica
}

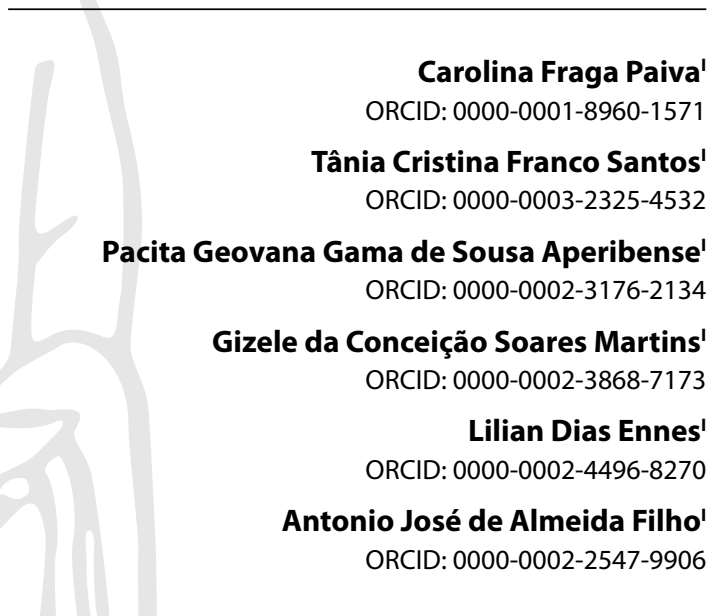

'Universidade Federal do Rio de Janeiro. Rio de Janeiro, Rio de Janeiro, Brazil.

How to cite this article:

Paiva FP, Santos TCF, Aperibense PGGS, Martins GCS, Ennes LD, Almeida Filho AJ. Historical aspects

in pain management in palliative care in an oncological reference unit. Rev Bras Enferm. 2021;74(5):e20200761. https://doi.org/10.1590/0034-7167-2020-0761

Corresponding author: Antonio José de Almeida Filho E-mail:ajafilhos@eean.ufrj.br

EDITOR IN CHIEF: Dulce Babrosa ASSOCIATE EDITOR: Maria Itayra Padilha

Submission: $08-12-2020$

Approval: 04-18-2021

\begin{abstract}
Objective: Describe the actions implemented for pain management in palliative care oncology and analyze the contribution of Hospital do Câncer IV, as a reference unit at the National Cancer Institute. Methods: Study of the history of the present time, whose sources were written documents and interviews with five participants. The collection took place from February to June 2018. The analysis of the written sources took place through internal and external criticism of the documents, considering their chronology and theme. Results: Professionals contributed with actions for pain management in palliative oncology care: in discussions and final drafting of ordinances, as rapporteurs at national and international events, in the elaboration of humanization conducts and systematization of assistance in addressing pain. Final considerations: These actions favored assistance in palliative oncology care at various levels of health care for patients and families, with greater technical and scientific recognition for all.

Descriptors: Palliative Care; History of Nursing; Life Quality; Medical Oncology; Cancer Pains.
\end{abstract}

\section{RESUMO}

Objetivo: Descrever as ações implementadas para o manejo da dor na assistência em cuidados paliativos oncológicos e analisar a contribuição do Hospital do Câncer IV, enquanto unidade de referência no Instituto Nacional de Câncer. Métodos: Estudo de história do tempo presente, cujas fontes foram documentos escritos e entrevistas com cinco participantes. A coleta ocorreu de fevereiro a junho de 2018. A análise das fontes escritas deu-se mediante crítica interna e externa aos documentos, considerando sua cronologia e temática. Resultados: Profissionais contribuíram com ações para o manejo da dor em cuidados paliativos oncológicos: nas discussões e redação final de portarias, como relatores em eventos nacionais e internacionais, na elaboração de condutas de humanização e sistematização da assistência na abordagem da dor. Considerações finais: Essas ações favoreceram a assistência em cuidados paliativos oncológicos nos vários níveis de atenção de saúde aos pacientes e familiares, com maior reconhecimento técnico e científico para todos.

Descritores: Cuidados Paliativos; História da Enfermagem; Qualidade de Vida; Oncologia; Dor do Câncer.

\section{RESUMEN}

Objetivo: Describir acciones implementadas al manejo del dolor en asistencia en cuidados paliativos oncológicos y analizar la contribución del Hospital do Câncer IV, mientras unidad de referencia en el National Cancer Institute. Métodos: Estudio de historia del tiempo presente, cuyas fuentes fueron documentos escritos y entrevistas con cinco participantes. Recolecta ocurrió de febrero a junio de 2018. Análisis de fuentes escritas mediante crítica interna y externa a documentos, considerando su cronología y temática. Resultados: Profesionales contribuyeron con acciones al manejo del dolor en cuidados paliativos oncológicos: en las discusiones y redacción final de decretos, como relatores en eventos nacionales e internacionales, en la elaboración de conductas de humanización y sistematización de la asistencia en el abordaje del dolor. Consideraciones finales: Esas acciones favorecieron la asistencia en cuidados paliativos oncológicos en los varios niveles de atención de salud a los pacientes y familiares, con mayor reconocimiento técnico y científico para todos. Descriptores: Cuidados Paliativos; Historia de la Enfermería; Calidad de Vida; Oncología Médica; Dolor en Câncer. 


\section{INTRODUCTION}

The first Palliative Care Service was officially opened, in Brazil, in 1991, at the National Cancer Institute (INCA) ${ }^{(1)}$. Records point to the country as the second in Latin America in which people with cancer report feeling the symptom of pain more, with cancer pain affecting $70 \%$ to $90 \%$ of patients who were in an advanced stage $^{(2-3)}$. This Service has developed over the years and, in 1998, gained exclusive space for specialized assistance. In that year, the construction of a new INCA unit was completed, exclusively for palliative care, initially called the Oncological Therapeutic Support Center (CSTO), whose name was changed, in 2004, to Cancer Hospital IV (HC IV) $)^{(4)}$.

That same year, a movement to reconfigure assistance and reorganize health services began, at HC IV, with a view to the accreditation process. The set of care activities offered was based on comprehensive and humanized care, from physical control to psychological suffering, whose goals were to improve the environment and working conditions of those involved in the care process, in search of qualified assistance at a high level of care. excellence, based on a holistic and humanized vision. This care was aimed at creating a safe and supportive environment, maintaining the dignity of the patient and family and limiting emotional and physical suffering, allowing individuals to choose $\mathrm{e}^{(5)}$.

It is noteworthy that the approach of the multidisciplinary team, the promotion of quality of life and the humanization of care, including the accompaniment in mourning, are extremely important for meeting human needs. This integration is a way of observing all dimensions of the patient and family; in addition, the composition of this team is relevant to develop an expanded and meaningful assistance ${ }^{(6-7)}$.

The World Health Organization (WHO), attentive to the needs of comprehensive and humanized assistance to the person in need of palliative care and his family, published, in 1986, ten principles that guided the performance of the multi-professional team in palliative care. Among them, pain management was recorded as follows:"promoting pain relief and other unpleasant symptoms"(6).

The importance of pain control was also recorded by WHO in its first publication defining palliative care, in 1990, reinforced in the redefinition in 2002 . Thus, an approach that aims at the quality of life of patients and their families should be considered, facing the problems associated with diseases with risk of death, through the prevention and relief of suffering. That is, this is done through early identification, evaluation and impeccable treatment of pain and other problems - physical, psychosocial and spiritual ${ }^{(8)}$.

Such care must focus on the relief of pain and suffering, directly associated with clinical conditions or the end of life, as they are symptoms considered serious, which compromise all physical, social or emotional functioning ${ }^{(9)}$. Thus, specific knowledge is required for pharmacological prescription or not, as well as for addressing psychosocial and spiritual aspects. All of these factors must be taken into account, contributing to the exacerbation or attenuation of symptoms ${ }^{(6)}$. In this context, in 2002 - following the national and international movement of pain management in palliative care as well as WHO publications and in view of the growing demands of pain management -, important ordinances were instituted to subsidize and encourage the development of this approach.
In view of the exposed historical situation, we present the following investigative question: What actions adopted for pain management contributed to the development of palliative cancer care in HC IV and what were the repercussions of these actions in $\mathrm{HC} \mathrm{IV}$ ?

\section{OBJECTIVE}

Describe the actions implemented for pain management in palliative care oncology care and analyze the contribution of $\mathrm{HC}$ IV, as a reference unit, at INCA.

\section{METHODS}

\section{Ethical aspects}

Ethical aspects were respected, as recommended by Resolutions 466/12 and 510/16 of the National Health Council, being approved by the Research Ethics Committees of the proposing and co-participating institution.

\section{Study type}

It is a study of the history of the present time, with a qualitative approach, whose corpus was composed of direct historical sources (written and oral); and indirect sources.

The time frame covers the years 2002 to 2005, a period in which publications of relevant ordinances for palliative oncology care took place and the participation of the director of the unit in its elaborations. In 2002, Ordinance No. 859, of November $12^{(10)}$, approved the clinical protocol and therapeutic guidelines, as well as the use of opiates in the relief of chronic pain, contributing to the management of pain in palliative care. In 2005, Ordinance No. 2,439 , of December $8^{(11)}$, introduced palliative care, for the first time, at all levels of national health care.

\section{Methodological procedures}

\section{Study scenario and data sources}

The scenario was the HC IV, INCA's reference and exclusive palliative care unit, in the city of Rio de Janeiro, state of Rio de Janeiro.

\section{Data collection and organization}

The total number of professionals who met the inclusion criteria was 12 . Of these, three refused to participate, one was on a medical certificate, one had died, so seven participated in the research. Among the sample group, five had excerpts from the interview presented for portraying content similar to those of the other participants, in direct contribution to the phenomenon studied in this article.

These were the inclusion criteria: professionals who held positions of leadership of services, including a doctor who held a leadership position in the management of the hospital; those who contributed to the elaboration of actions that strengthened and supported pain management in palliative oncology care, according to the time frame of this research. Participants were 
identified by accessing the staff and by referring others from the sample group.

The interviews were carried out from February to June 2018. The instrument that guided them followed a pre-established script, addressing issues related to the development of actions that strengthened and supported pain management in palliative oncology care. The technique used was Thematic Oral History. The interviews - preceded by the signature of the Informed Consent Form - were recorded digitally and, later, transcribed and validated by the participants, through reading and written authorization for use. The location was defined by the participants, and the average time was 65 minutes. In the identification, the initial letter of the profession was used, followed by the Arabic number corresponding to the sequential order of the interviews: nurses (E1; E2; E3; E4); medical (M1).

The written sources comprised: Ordinance No. 859, of November 12, 2002 ${ }^{(10)}$; Ordinance No. 2,439, of December 8, 2005(11); 2005 annual management report of HC IV; 2004 Nursing Division Management report; having also been selected on the official website and in the HC IV/INCA collection. The indirect sources consisted of articles from scientific journals produced on the subject. The study followed the COREQ guidelines.

\section{Data analysis}

The data were organized, classified, and analyzed in accordance with the historical method. The written sources were analyzed through internal and external criticism of the documents, in order to assess their veracity and the validity of the information contained therein, as well as to guarantee their interpretation according to the reality in which they were produced, seeking to eliminate or make explicit any contradictions ${ }^{(12)}$. The reliability of the results was ensured with the valorization of the documentary set - and not by the documents alone -, considering the chronology and the theme/content. In view of this, the following axes emerged: publications related to pain management; leadership of the unit related to humanization initiatives; and strengthening representativeness on the national scene. The data were analyzed based on articles on the topic, useful for understanding the context in which the sources were produced, aiming to apprehend the discourse contained in the texts, that is, the indirect sources.

\section{RESULTS}

All research participants had at least one specialization in the area, broken down as follows: four with a specialization in Nursing, along the lines of residency, by the National Cancer Institute (INCA); two with a specialization in Nursing in Oncology, by INCA; a specialization in Infectious and Parasitic Diseases, by Fundação Oswaldo Cruz (FIOCRUZ); one specializing in Oncology Nursing Residency in the Palliative Care Area, by INCA; one with a specialization in the molds Medical residency in oncology surgery by INCA, coloproctological surgery by the Hospital dos Servidores do Estado and Medical residency in general surgery by the Hospital Geral de Jacarepaguá. All participants were graduated in nursing and medicine, with an average working time at the institution, until the time of data collection, of 15.2 years.
The practices related to pain management in palliative oncology care aimed to promote the quality of life of patients and their families, having professional support through assistance with measures of comfort and relief of physical, psychosocial, and spiritual suffering, capable of providing understanding of the finitude of life. Such practices required great investment in the elaboration of the professionals' actions within the first exclusive palliative care unit in Brazil.

In this perspective, it was necessary to adapt the care supported by publications made available by WHO, referring to pain management in palliative care. The interview excerpt shows the participation of HC IV professionals in the development of activities related to humanization and pain care, which officially contributed as a model of national assistance:

We were going to do a pain ordinance and a palliative care ordinance, but the palliative care ordinance did not happen [...] all the other ordinances that we started for palliative care I participated in [...] I was there elaborating the 2002 ordinance, of pain [Ordinance No. 859, of November 12, 2002]. I was the one who was going to do it [at the Ministry of Health] [...] I was representing INCA [...] it was the only ordinance that has [pain] initial pain ordinance that talks about morphine use, opioid use [...] specifically for use of analgesic drugs [...]. I was participating in this ordinance [...] it is still in use today and it was built at the Ministry of Health, in Brasilia [...]. (M1)

The continuity of participation in the development of these actions was recorded, again, by the director of HC IV, highlighting priority to the humanization of care and the strengthening of the interpersonal relationship, which is configured as the main activity for the promotion of quality of care. The actions were aimed at adopting pharmacological and non-pharmacological measures:

Humanization, at that time [...] we had here [at HC IV] Pet's day [the day when HCIV took animals to visit hospitalized patients]. [...] We had music for the patients [...] the musicians, harpers, flutists went to perform once a month [...]. There was a patient who had VAS 10 [Visual Pain Scale] up there [in the infirmary], she went down and started to do the activities and there was no more pain [...]. Pain is multifactorial [...] people embraced that space, there was time that there were 20 patients doing activity there [...]. (M1)

They were also described by another participant:

[...] We worked a lot on this part of humanization [...]. It offered qualified assistance [...] the most important was the patient and the family. The patient with advanced cancer, you have to give the best [...]. Another important thing in the humanization process is that each floor of the ward was painted in a color [...] to encourage patients and family members. There was a lilac floor, another water green [...] For them to think that it was not just a hospital environment. [...] I had a day to play music [...] it was very good for everyone [...] this is all humanization. (E3)

The actions developed by the professionals, related to humanization initiatives and also centered on pain relief, left the internal institutional sphere for contribution at the national level, strengthening the unit's attributions in the Ministry of Health 
$(\mathrm{MOH})$. The excerpt from the following interview confirms these actions:

[...] Within humanization, we had to act according to the Ministry of Health's booklet on humanization, so we worked within that booklet. [...]. So, within this booklet, we started to participate, and then there was the humanization congress, and I was asked to speak. We participated in humanization meetings together with the Ministry [...] we had big meetings [...] the meetings left the INCA limit and went to other federal hospitals [...] there was a bad news communication book that was very based on what we used to do it here [at HCIV], this book is not from HCIV, but it was built on the expertise of HCIV's professional performance, it was especially useful [...]. (M1)

In addition to traveling to events, the professionals represented the unit in important positions at the tables and also as speakers at the events:

I traveled, I went to many events, I traveled twice to the South to participate in the congresses, in nursing week [...]. And the people at HCIV were well represented [...] we participated in several pain tables, dressing tables [...] it gave the girls [or other nurses] the opportunity, but always together with them, setting up the lectures [...] we did a Forum, at UERJ [State University of Rio de Janeiro], which was almost a week [...] we did several lectures talking about palliative care and humanization [...] each nurse talking about an area [...] I went to the Brazilian Nursing Congress; [...] For international congress; [...] We went to INCA [HCI] to teach nursing residents [...]. (E3)

Another action described was the reception of professionals from other hospitals, who moved to HC IV with the intention of improving their palliative care practices.:

[...] there was a group, also from Ipanema Hospital, who came to train with us [...] this group came to do training with our team [...] at their hospital they created a palliative care service [...] they went to visit and know how was that it was the technical part of $H C I V$, about pain assessment, subcutaneous hydration that, at the time, nobody did [...]. (E4)

Several actions have also contributed to pain management in palliative oncology care, such as the holding of two events in the second half of 2004: the I Forum of the 5th Vital Sign, which took place on August 20; and the 1st International Congress on Palliative Care and Pain - Humanization: a matter of respect. Both were recorded in the Annual Report of HC IV, referring to the activities of 2004: "Increase of 7\% in the consultations of the Home Visit; Opening of the HC IV Auditorium; Creation of the Pain Group, to improve the monitoring of patients with constant pain; 5th Vital Sign Forum; International Congress on Palliative Care and Pain; Creation of the Nursing Division; Creation of the Tumor Dressings and Ostomy Clinic"(4).

The registration of the international event was also carried out on the official INCA website, with greater detail. The director general of INCA, José Gomes Temporão, on October 21, 2004, at 6 pm, proceeded to the opening of the "International Congress on Palliative Care and Pain - Humanization: a matter of respect". On the occasion, an agreement would be signed for the exchange between professionals from INCA and the Spanish hospital Gran Canaria Dr. Negrin, represented by its director Marcos Gómez Sancho, an international exponent in the field of palliative medicine and the author of several books on the subject. The event took place between October 21 and 23, 2004.

These actions were also reported in the following interview, in which the participant referred to her role in planning, creating, and participating during the events.:

In 2004, in my management, when I created the Nursing Division, we managed to make the I Forum of the 5th Vital Sign [...] the HC IV that created [...]. I organized everything [...] the first hospital to hold a Forum of the 5th Vital Sign was HCIV [...] it was very good because the participation of palliative care at the level of Brazil was disclosed. [...] We also had the 1st International Congress on Palliative Care and Pain [...] a big event here in Rio de Janeiro [...] a lot of people came from outside [...] we had a Pre-Congress Nursing Course [...] wound tables, pain table [...] everything always with the participation of nursing, multidisciplinary team, doctor, social service [...] It was after the 1st International Palliative Care Congress that nursing showed what it could do to improve the quality of life of the cancer patient [...]. (E3)

Another participant registers the presence of internationally recognized professionals:

[...] We did the 1st International Congress of Palliative Care in Brazil [...] we brought several people [...] came Marcos Gomes Sancho, an exemplary figure in palliative care, he is a Spanish anesthetist and has a hospice in Gran Canaria, Spain [...] He is one of the popes of palliative care [...] Sebastiano Mercadante came [...] he has a hospice in Italy. [...] It talks about controlled sedation [...] one of the popes of pain in the world [...]. (M1)

These actions, in parallel with the development of the events, strengthened and evidenced pain management in palliative care at HC IV; and also contributed to the reconfiguration of assistance by implementing a specific protocol for pain assessment and recording:

Pain control has always been our focus, very strong [...] We have revised our form in order to leave room for the beginning of the [pain] assessment [...] what we offered, the pain response and the record [in the form] [...] We remodeled our form [...] we had a stamp called the EVA stamp [Visual Analogue Scale] [...] we were concerned that, when administering [the drug], [...] knowing the same location of the dose and the EVA [...] Reassess and record after 40 [minutes] to an hour [...] then we attach a nursing prescription sheet. (E2)

A strategy in the development of these actions was the creation of tools to support professionals in favor of the quality of the assistance offered.:

[...] we created stamps of the 5th Vital Sign to be used in developments [...] we trained the technicians on how to assess [the pain] and take notes [...] they were trained on how to assess [...] always training everyone. (E3) 
[...] these changes were already coming, but some things had to improve [...] the technical part, routines, documentation [...] A lot was already done, but it wasn't written [...] the Division together with the team did a lot of internal training with everyone, with the nursing team, with nurses and technicians [...] there was a lot of investment in the questions of the classes [...] we had training on pain, on subcutaneous hydration, palliative care and what was this care once a month [...]. (E1)

In the following year, in 2005, an important ordinance was published (Ordinance No. 2,439, of December 8), also with the participation of a professional from HC IV/INCA, determining the insertion of palliative care in all levels of health care in Brazil:

Ordinance No. 2,439, of December 8, 2005, which revoked Ordinance No. 3,535, of September 2, 1998, and instituted the National Policy for Oncological Care, was built within INCA [...]. The National Oncology Care Policy was built within INCA and we took it there [Ministry of Health, in Brasilia] [...] the palliative care part has my participation [...] This ordinance was a milestone [...] placed palliative care in all levels of health care [...] the entire INCA worked together, the director general of INCA and the palliative care part, I participated [...] INCA was within the Ministry [of Health], there was an office inside [...] The INCA that made the Policies [...]. All the policies related to oncology were the ones that did the INCA [...] it was an organ for them. (M1)

\section{DISCUSSION}

HC IV, in Brazil, constituted an important space, which brought together a group of professionals whose expertise put him in a position to act as an authorized spokesman regarding palliative oncology care. This is because, since 1990, under the Organic Health Law No. 8,080, INCA was included as a reference body to assess and establish parameters for the provision of health services ${ }^{(13)}$. In this capacity, he led the development and creation of several internal, strategic actions and publications focusing on the first principle of WHO palliative care: "promoting pain relief and other unpleasant symptoms". With that, it reaffirmed the importance of providing specialized and excellent assistance.

Regarding the qualification of this care, $\mathrm{HC} \mathrm{IV}$ was supported by publications such as the "Ten Principles", by WHO; and Ordinance No. 881, of June 19, 2001, which instituted the National Program for the Humanization of Hospital Assistance ${ }^{(14)}$, whose objective was to promote the humanization of assistance in hospital spaces. Since then, initiatives for planning humanized care actions - aimed at qualified comprehensive care and pain management - have taken place through the director's contribution at the time, with emphasis on the discussion and final version of Ordinance No. 859 , of 12 November $2002^{(10)}$.

Such contribution seems to us to be related to the director's connection with INCA during her medical training and throughout her professional life. In addition, it has accumulated an important volume of scientific capital in the field of palliative care, which has been updated and expanded as a result of its experience at St. Christopher's Hospice, founded by Cicely Saunders (pioneer of palliative care in the world), in addition to studies in Brazil and other countries that developed this type of assistance. The acquisition of scientific capital is understood, in terms of specialization, through a systematic process of inculcation that, over time, was incorporated by $\mathrm{it}^{(15)}$.

The scientific capital of HC IV professionals, related to pain relief, represents an advance in palliative cancer care, as unrelieved pain is a critical public health problem. With regard to pharmacological treatment, opioids are among the most powerful and widely available drugs, constituting the mainstay of the treatment of moderate to severe cancer pain ${ }^{(16)}$. Regarding pharmacological measures, the WHO published a list of drugs, doses and routes of administration for assistance in palliative care $^{(9)}$, the first being published in $1977^{(17)}$. The purpose of this list was to guide countries regarding the prioritization of products and their wide availability and accessibility to cancer patients in all health systems ${ }^{(18)}$.

It is worth considering the importance of the pharmacological approach aimed at pain relief and interventions in physical and psychological symptoms. One of the recommendations in patients with advanced cancer refers to the importance of adequate relief through the use of opioid analgesics to improve quality of life ${ }^{(16)}$. However, there is a huge difference between the need and the availability of opioids, which increases considerably when it comes to people living in low and middle socioeconomic income countries ${ }^{(9)}$.

Therefore, in view of this situation of need and availability of opioids, the importance of designing and implementing laws, regulations and guidelines that include the safe management of controlled drugs is highlighted, preventing unnecessary barriers of access for patients; in addition, it is relevant to support services that develop palliative care ${ }^{(4)}$. Despite the scientific evidence that supports the use of opioids in the control of cancer pain ${ }^{(19-20)}$, and also the WHO recommendations to ensure adequate availability, studies have reported that $75 \%$ of the world population still need adequate access to these analgesics ${ }^{(21)}$.

In this context, in Brazil, the approval of the clinical protocol and therapeutic guidelines stands out, regulating the use of opioids through the publication of Ordinance No. 859, of November 12, $2002^{(10)}$, developed with the participation of professionals from the HC IV. The Ordinance recorded the general concept of the disease, criteria for inclusion/exclusion of patients, diagnostic criteria, therapeutic scheme and mechanisms for monitoring and evaluating this treatment. Being of national character, it should be used by the Health Departments of the states, the Federal District and the municipalities, in the regulation of the dispensation of medicines ${ }^{(10)}$.

Early identification, assessment and treatment of pain are relevant, in view of the WHO definition of palliative care as an approach that, in addition to promoting the quality of life of patients and their families, contributes to coping, through prevention and relief from suffering, from advanced diseases that threaten the continuity of life ${ }^{(22)}$.

With the active participation of nurses and nursing technicians, the initiative of the group of professionals, committed to the development of actions with a strong impact on the quality of care and focused on pain management and comprehensive care, gave itself specialized knowledge and, thus, also a prominent position in the oncological field. Thus, they acted as legitimate spokespersons in the treatment of pain in palliative oncology care 
in the country. As HC IV professionals diversified and strengthened care actions, with special attention to pain management and comprehensive care for patients and family members, they also shared this knowledge with other institutions in the country.

According to the $\mathrm{WHO}$, the lack of adequate pain care is a public health problem. It is estimated that patients with advanced cancer suffer without specific treatment for moderate to severe pain, the relief of which cannot be achieved without improving the availability and accessibility of opioids ${ }^{(23)}$. Alongside this, it is important to encourage education and awareness campaigns, development and implementation of comprehensive palliative care, pain management and management guidelines and national plans ${ }^{(9)}$.

HCIV's involvement also occurred through actions that stimulated the development of technical and scientific knowledge, through internal events, such as the I Forum of the 5th Vital Sign and the I International Congress of Palliative Care in Brazil, as well as participation in external events ${ }^{(1,4)}$. Thus, HC IV supported itself in the development of these proposals, maintaining its effort and participation in carrying out and disseminating activities. The actions related to the creation, development and support of humanization initiatives, with a focus also on pain relief, left the internal sphere to contribute to the development of palliative care at the national level(4), affirming its role as a technical and executive instance of the $\mathrm{MOH}$.

In these events, the performance and strategies in palliative oncology care were discussed in relation to pain; in addition, the unit planned to include it, in routine records, as the fifth vital sign. In this way, care protocols were improved through the insertion of new strategies in the approach to care - with an effect on the quality of pain management - and by increasing the visibility of $\mathrm{HC}$ IV, both in front of other INCA units and before other hospital institutions throughout the national territory ${ }^{(1)}$.

Therefore, the importance of looking beyond the presence or absence of evidence for analgesic therapy is stressed, as pain causes not only physical suffering, but also mental suffering. Still, it is directly influenced by the patient's bio-psycho-sociocultural context, the origin and complicating factors being equally considered for the treatment ${ }^{(24)}$. In this context, pain has a major impact on health and quality of life. Therefore, it is necessary to have culturally adapted and validated instruments that specifically measure knowledge about the management of chronic pain, being of great relevance to support and direct the professional, since the level of knowledge of painful conditions can influence the way they are treated ${ }^{(25)}$.

The pain is immeasurable, and several factors are related to the stage of the disease. Assessing the difference in intensity facilitates the understanding of pain reduction in cancer patients during repeated hospitalizations ${ }^{(26)}$. Pain management is complex and multifactorial, so a deeper understanding of the barriers to adequate and ideal treatment needs to be obtained to remedy the deficiencies among professionals ${ }^{(27)}$. Thus, the actions implemented aiming at pain management were adequate and effective to improve care for cancer patients and ensured comprehensive care, as well as holistic and humanized care.

Some participants also narrated the development of care actions with a non-pharmacological approach, which were in line with $\mathrm{WHO}$ recommendations, with a view to comprehensive and humanized care. Among these, there are actions that were directly reflected in care, such as a warm and pleasant environment to be in, contact with animals, music and an entire space for carrying out activities. The initiative to create this space was based on the experience of the doctor (director at HC IV at the time) as a researcher of national reference, when she was at the hospice of world reference, St. Christopher's.

In parallel to the aforementioned initiatives, humanization was an important tool for the benefit of users, workers and managers in the health production process, providing value to those involved. In addition, it provided autonomy, aiming to transform the reality in which they lived through collective participation in management and production processes. Humanizing is closely related to the element of a holistic approach, it refers to the need to take into account all the biopsychosocial and spiritual dimensions of the patient, the disease and the care ${ }^{(28)}$. Taking care of the patient's pain does not mean exclusively performing technical procedures: it requires showing interest, compassion and effectiveness ${ }^{(29)}$.

\section{Study limitations}

The limitations of the study are the impossibility of accessing other historical documents (perhaps, discovered in the future) despite the intense investment made in the search for these materials, which would allow adjustments to the historical version now presented.

\section{Contributions to the nursing field}

The contribution of this study consists of highlighting the need for careful reflection regarding the care support focused on the management of cancer pain, which could be used by health professionals at all levels of care. It also contributed to the expansion of the knowledge of those who work in this area, in order to promote a greater possibility of understanding and appropriating this approach, aiming at the quality of health care at all levels. This work also serves as an important analytical tool to broaden the understanding of the trajectory of nursing in this type of assistance in the country.

\section{FINAL CONSIDERATIONS}

The participation in the discussions and the final text of Ordinance No. 859, of November 12, 2002, in addition to the constant updating of professionals, in the organization and execution of events and courses aimed at palliative oncology care - with emphasis on pain management -, supported the assistance of this type of care at all levels of health care. That is, such events were able to redesign the care related to the management of total pain in patients with advanced cancer, in all dimensions (physical, psychological, social and spiritual) of a person.

In addition, the importance of publications, ordinances and standardization of care protocols is perceived for the development of care - with a focus on pain, within HC IV -, as these, in addition to systematizing the attributions and care, reflected directly in the 
context in which that the unit was a national reference (by means of the Organic Health Law), as an organ of the Ministry of Health responsible for the standardization of cancer control actions.

The humanization of care and the strengthening of interpersonal relationships, which are important aspects for the quality of care, involved pharmacological and non-pharmacological measures. Among the latter, were: Pet Day, when animals were allowed to visit inpatients; monthly music sessions for patients, featuring harpists, flutists. In addition, each floor of the infirmary was painted in a different color for greater well-being of patients and family members.

It is possible to show that, in the study, professionals contributed to the development of publications and new protocols, aiming at a better quality of care routine. Furthermore, it constituted a fruitful scenario for the development of the principle related to pain in palliative care, published by $\mathrm{WHO}$, with a view to the evolution and national strengthening of palliative care in the face of the challenges that were imposed.

The performance of HC IV professionals was also marked by actions that contributed to the technical and scientific development of palliative oncology care for professionals from other health institutions, national and foreign. Thus, they organized and held an event both national (the I Forum of the 5th Vital Sign) and international (the I International Congress of Palliative Care in Brazil), in addition to participating in external events. With that, HC IV consolidated a prominent condition in a field of specialized knowledge.

It is concluded that, in HC IV, professionals participated in the implementation of effective actions in view of the challenges inherent to palliative oncology care and pain management. Thus, they consolidated the technical and scientific recognition of that INCA unit in this field of specialized care, as a reference in the Brazilian health scenario. Likewise, HC IV professionals have also capitalized on the effects of working at a national and international reference institution.

\section{FUNDING}

This work was carried out with the support of the Coordination for the Improvement of Higher Education Personnel (Capes).

\section{REFERENCES}

1. Instituto Nacional de Câncer. Hospital do Câncer IV (HC IV) [Internet]. 2019[cited 2019 Aug 10]. Available from: http://www1.inca.gov.br/ impressao.asp?op=cv\&id $=233$

2. Cunha FF, Rêgo LP. Nursing and cancer pain. Rev Dor. 2015;16(2):142-5. https://doi.org/10.5935/1806-0013.20150027

3. Oliveira AL, Palma SN, Cunha BAS. Chronic cancer pain management by the nursing team. Rev Dor. 2016;17(3):219-222. https://doi. org/10.5935/1806-0013.20160075

4. Instituto Nacional de Câncer (INCA). Relatório de anual 2004. Rio de Janeiro: Instituto Nacional de Câncer; 2004. 171p.

5. Rogers IR, Lukin B. Applying palliative care principles and practice to emergency medicine. Emerg Med Australas. 2015; 27(6):612-5. https:// doi.org/10.1111/1742-6723.12494

6. Academia Nacional de Cuidados Paliativos (ANCP). Manual dos cuidados paliativos [Internet]. 2012[cited 2020 May 10]. Available from: http://biblioteca.cofen.gov.br/wp-content/uploads/2017/05/Manual-de-cuidados-paliativos-ANCP.pdf

7. Silva AF, Issi HB, Motta MGC, Botene DZA. Palliative care in paediatric oncology: perceptions, expertise and practices from the perspective of the multidisciplinary team. Rev Gaúcha Enferm. 2015;36(2):56-62. https://doi.org/10.1590/1983-1447.2015.02.46299

8. World Health Organization (WHO). National cancer control programmes: policies and managerial guidelines[Internet]. 2002. [cited 2020 May 10]. Available from: https://www.who.int/cancer/publications/nccp2002/en/

9. Knaul FM, Farmer PE, Krakauer EL, Lima L, Bhadelia A, Kwete XJ, et al. Alleviating the access abyss in palliative care and pain relief-an imperative of universal health coverage: the Lancet Commission report. Lancet. 2018;391(10128):1391-454. https://doi.org/10.1016/S0140-6736(17)32513-8

10. Ministério da Saúde (BR). Portaria n. ${ }^{\circ}$ 859, de 12 de novembro de 2002. Aprova o Protocolo Clínico e Diretrizes Terapêuticas, o uso de opiáceos, codeína, morfina e metadona, no alívio da dor crônica e dá outras providencias. Diário Oficial da República Federativa do Brasil. 2002.

11. Ministério da Saúde (BR). Portaria n. ${ }^{\circ}$ 2.439/GM, de 8 de dezembro de 2005. Institui a Política Nacional de Atenção Oncológica: promoção, prevenção, diagnóstico, tratamento, reabilitação e cuidados paliativos, a ser implantada em todas as unidades federadas, respeitadas as competências das três esferas de gestão [Internet]. 2005[cited 2020 Aug 28]. Available from: https://bvsms.saude.gov.br/bvs/saudelegis/ gm/2005/prt2439_08_12_2005.html

12. Lemos FCS, Galindo D, Reis Jr LP, Moreira MM, Borges Magalhães AG. Análise documental: algumas pistas de pesquisa em psicologia e história. Psicolestud [Internet]. 30 de setembro de 2015 [cited 2020 Aug 28];20(3):461-9. Available from: http://www.periodicos.uem.br/ojs/ index.php/PsicolEstud/article/view/27417

13. Presidência da República (BR). Lei n॰ 8.080, de 19 de setembro de 1990. Dispõe sobre as condições para a promoção, proteção e recuperação da saúde, a organização e o funcionamento dos serviços correspondentes e dá outras providências [Internet]. 1990 [cited 2020 Apr 28]. Available from: http://www.planalto.gov.br/ccivil_03/leis/l8080.htm

14. Ministério da Saúde (BR). Portaria n. ${ }^{8} 81 / \mathrm{GM}$, de 02 de setembro de 1998. Estabelece critérios para cadastramento de centros de atendimento em oncologia. 1998.

15. Grenfell M. Pierre Bourdieu: conceitos fundamentais. Petrópolis, RJ: Vozes; 2018. 
16. Yen TY, Chiou JF, Chiang WY. Proportional dose of rapid-onset opioid in breakthrough cancer pain management: an open-label, multicenter study. Medicine (Baltimore). 2018;97(30):e11593. https://doi.org/10.1097/MD.0000000000011593

17. Fundação Oswaldo Cruz (Fiocruz). Ministério da Saúde lança nova lista de medicamentos essenciais [Internet]. 2007 [cited 2020 May 3]. Available from: https://agencia.fiocruz.br/minist\%C3\%A9rio-da-sa\%C3\%BAde-lan\%C3\%A7a-nova-lista-de-medicamentos-essenciais

18. World Health Organization (WHO). Strengthening access to essential medicines [Internet]. 2002 [cited 2020 May 23]. Available from: https:// www.who.int/selection_medicines/committees/expert/22/en/

19. Silva LJ, Mendanha DM, Gomes PP. The use of opioids in the treatment of oncologic pain in the elderly. BrJP. 2020;3(1):63-72. https://doi. org/10.5935/2595-0118.20200014

20. Wiffen PJ, Wee B, Moore RA. Oral morphine for cancer pain. Cochrane Database Syst Rev. 2016;22(4). https://doi.org/10.1002/14651858. CD003868.pub4

21. Berterame S, Erthal J, Thomas J, Fellner S, Vosse B, Clare P, et al. Use of and barriers to access to opioid analgesics: a worldwide, regional, and national study. Lancet. 2016;387(10028):1644-56. https://doi.org/10.1016/S0140-6736(16)00161-6

22. World Health Organization (WHO). WHO definition of palliative care [Internet]. 2020[cited 2020 May 20].Available from: http://www.who.int/ cancer/palliative/definition/en/

23. Cleary JF, Maurer MA. Pain and policy studies group: two decades of working to address regulatory barriers to improve opioid availability and accessibility around the world. J Pain Symptom Manage. 2018;55(2S):S121-S134. https://doi.org/10.1016/j.jpainsymman.2017.03.029

24. Deng G. Integrative Medicine Therapies for Pain Management in Cancer Patients. Cancer J. 2019;25(5):343-8. https://doi.org/10.1097/ PPO.0000000000000399

25. Pancorbo-Hidalgo PL, Bellido-Vallejo JC. Psychometric evaluation of the nursing outcome knowledge: pain management in people with chronic pain. Int J Environ Res Public Health. 2019;16(23):4604. https://doi.org/10.3390/ijerph16234604

26. Wang WY, Chu CM, Wu YS, Sung CS, Ho ST, Pan HH, et al. Evaluation of the pain intensity differences among hospitalized cancer patients based on a nursing information system. PLoS One. 2019;14(9):e0222516. https://doi.org/10.1371/journal.pone.0222516

27. Schroeder DL, Hoffman LA, Fioravanti M, Medley DP, Zullo TG, Tuite PK. Enhancing Nurses Pain Assessment to Improve Patient Satisfaction. Orthop Nurs. 2016;35(2):108-19. https://doi.org/10.1097/NOR.0000000000000226

28. Busch IM, Moretti F, Travaini G, Wu AW, Rimondini M. Humanization of care: key elements identified by patients, caregivers, and healthcare providers. a systematic review. Patient. 2019;12(5):461-474. https://doi.org/10.1007/s40271-019-00370-1

29. Silveira NB, Silveira RS, Avila LI, Gonçalves NGC, Lunardi VL, Enderle CF. Procedimentos Terapêuticos de Enfermagem no Contexto da dor: percepção dos pacientes. Enferm Foco. 2016;7(1):61-6. https://doi.org/10.21675/2357-707X.2016.v7.n1.669 